\title{
New proposals for the design of steel beam-columns in case of fire, including a new approach for the lateral-torsional buckling
}

\author{
N. Lopes ${ }^{a}$, L. Simões da Silva ${ }^{b}$, P.M.M. Vila Real ${ }^{a, *}$, P. Piloto ${ }^{c}$ \\ ${ }^{a}$ Department of Civil Engineering, University of Aveiro, 3810 Aveiro, Portugal \\ ${ }^{\mathrm{b}}$ Department of Civil Engineering, University of Coimbra, 3030-290 Coimbra, Portugal \\ ${ }^{\mathrm{c}}$ Department of Mechanical Engineering, Polytechnic of Bragança, Bragança, Portugal
}

\begin{abstract}
The possibility of having, in parts 1-1 and 1-2 of Eurocode 3, the same approach for the design of beam-columns and for lateral-torsional buckling, was investigated by the authors in previous papers using a numerical approach, where it was concluded that those assumptions could be made.

In the present paper, a new approach for lateral-torsional buckling has been used with the formulae for the design of beam-columns at elevated temperature based on prEN 1993-1-1 combined with the formulae from prEN 1993-1-2. In both cases the results obtained are much better than the current design expressions, when compared with those obtained in the numerical calculations.
\end{abstract}

Keywords: Steel; Beam-column; Lateral-torsional buckling; Fire; Eurocode 3; Numerical modelling

\section{Introduction}

The final draft of part 1-1 of Eurocode 3, prEN 19931-1 (2003) [1], introduced several changes in the design formulae for beam-columns and unrestrained beams with lateral-torsional buckling (LTB) at room temperature. These modifications took place during the conversion of Eurocode 3 from ENV to EN status.

Two new formulae for the design of beam-columns at room temperature have been proposed in prEN 1993-1-1 (2003) [1] as the result of extensive work by two working groups that followed different approaches, namely, a French-Belgian team and an Austrian-German one.
Under fire conditions, in prEN 1993-1-2 (2003) [2], the proposed formulae for the design of beam-columns in case of fire have not changed and are still based on ENV 1993-1-1 (1992) [3].

In order to study the possibility of having, in parts 1-1 and 1-2 of the upcoming Eurocode 3, the same approach for beam-columns, a numerical investigation was carried out, with the conclusion that it is possible to use the formulae from the part 1-1 provided that some factors are modified to consider high temperatures [4].

Significant changes, proposed in prEN 1993-1-1 (2003) [1], have been introduced in the evaluation of the lateral-torsional buckling resistance of unrestrained beams at room temperature leading to results that are still on the safe side but less conservative than those obtained using the approach prescribed in ENV 1993-11 (1992) [3] in the case of non-uniform bending. 


\begin{tabular}{|c|c|c|c|}
\hline \multicolumn{4}{|c|}{ Nomenclature } \\
\hline$A$ & area of the cross-section & $\beta_{\mathrm{M}, \mathrm{LT}}$ & equivalent uniform moment factor corre- \\
\hline E & Young's modulus & & sponding to lateral-torsional buckling \\
\hline$f_{y}$ & yield strength & $\beta_{\mathrm{M}, y}$ & equivalent uniform moment factor for the $y$ \\
\hline$k_{y y}$ and & $k_{z y}$ interaction factors that can be determined & & axis \\
\hline$k_{y, \theta}$ & $\begin{array}{l}\text { according to the two methods } \\
\text { reduction factor for the yield strength at } \\
\text { temperature } \theta_{a}\end{array}$ & $\Delta M_{y, \mathrm{Ed}}$ & $\begin{array}{l}\text { moments due to the shift of the centroidal } \\
\text { axis, which are equal to zero in case of } \\
\text { classes } 1,2 \text { and } 3\end{array}$ \\
\hline$k_{\mathrm{E}, \theta}$ & reduction factor for the slope of the linear & $\gamma_{\mathrm{M} 0}$ & partial safety factor (usually $\gamma_{\mathrm{M} 0}=1.0$ ) \\
\hline$M_{\text {SAFIR }}$ & $\begin{array}{l}\text { elastic range at temperature } \theta_{a} \\
\text { resistant moment in the fire design situation }\end{array}$ & $\gamma_{\mathrm{M}, \mathrm{fi}}$ & $\begin{array}{l}\text { partial safety factor for the fire situation } \\
\text { (usually } \gamma_{\mathrm{M}, \mathrm{fi}}=1.0 \text { ) }\end{array}$ \\
\hline & given by SAFIR & $\bar{\lambda}_{\mathrm{LT}}$ & non-dimensional slenderness for lateral- \\
\hline$M_{y, \mathrm{fi}, \mathrm{Ed}}$ & $\begin{array}{l}\text { design bending moment about } y \text { axis for the } \\
\text { fire design situation }\end{array}$ & $\bar{\lambda}_{\mathrm{LT}, \theta}$ & $\begin{array}{l}\text { torsional bucking at room temperature } \\
\text { non-dimensional slenderness for lateral- }\end{array}$ \\
\hline$M_{y, \mathrm{fi}, \theta, \mathrm{Rd}}$ & $\begin{array}{l}\text { design moment resistance about } y \text { axis of } \\
\text { Class } 1 \text { or } 2 \text { cross-section at uniform tem- } \\
\text { perature } \theta_{a}\end{array}$ & $\chi_{\mathrm{LT}, \mathrm{fi}}$ & $\begin{array}{l}\text { torsional buckling at temperature } \theta_{a} \\
\text { reduction factor for lateral-torsional buck- } \\
\text { ling in the fire design situation }\end{array}$ \\
\hline$N_{\mathrm{fi}, \mathrm{Ed}}$ & $\begin{array}{l}\text { design axial force for the fire design situa- } \\
\text { tion }\end{array}$ & $\chi_{\min , \mathrm{fi}}$ & $\begin{array}{l}\text { minimum reduction factor of the } y \text { and } z \\
\text { axis for flexural buckling in the fire design }\end{array}$ \\
\hline$N_{\mathrm{fi}, \theta, \mathrm{Rd}}$ & design axial force resistance at uniform & & situation \\
\hline$W_{\mathrm{el}, y}$ & $\begin{array}{l}\text { temperature } \theta_{a} \\
\text { elastic section modulus for the } y \text { axis }\end{array}$ & $\chi_{y, \mathrm{fi}}$ & $\begin{array}{l}\text { reduction factor of the } y \text { axis for flexural } \\
\text { buckling in the fire design situation }\end{array}$ \\
\hline$W_{\mathrm{pl}, y}$ & plastic section modulus in $y$ axis & $\chi_{z, \mathrm{fi}}$ & reduction factor of the $z$ axis for flexural \\
\hline Greeks & & & \\
\hline$\alpha$ & imperfection factor & & \\
\hline
\end{tabular}

Numerical modelling of the lateral-torsional buckling of steel beams at elevated temperature has shown that the beam design curve from prEN 1993-1-2 (2003) [2] is over-conservative for bending moment diagrams other than uniform bending moment [5].

In accordance with the safety format of the lateraltorsional buckling code provisions for room temperature design, an alternative proposal for rolled sections or equivalent welded sections subjected to fire was presented by Vila Real et al. [5], that addressed the issue of the influence of the loading type on the resistance of the beam, leading to better agreement with the real behaviour while maintaining safety.

The objective of the present paper is to evaluate the proposals made by Vila Real et al. [4] in terms of a consistent safety check for the stability of beam-columns subjected to lateral-torsional buckling under fire loading, but using the new proposal for lateral-torsional buckling of unrestrained beams in case of fire [5]. This new proposal will be also used with the design formulae for beam-columns from the prEN 1993-1-2 (2003).

More specifically, using the specialised finite element code SAFIR [6], results of second-order analysis, including imperfections, for a range of lengths, levels of axial force and loading cases, are compared with the codified interaction formulae from part 1-2 of Eurocode 3 [2] (here denoted "prEN 1993-1-2" when the new proposal for lateral-torsional buckling [5] is not considered and "prEN 1993-1-2/f" when this new proposal is included) and with the proposed adaptation [4] to fire loading of method 1 and method 2 in prEN 1993-1-1 (2003), henceforth denoted "EC3 Method 1, fi/f" and "EC3 Method 2, fi/f" or "EC3 Method 1, fi" and "EC3 Method 2, fi", again if the new proposal for LTB [5] is considered or not. Finally, the safety of these proposals is discussed and established.

\section{Numerical model}

\subsection{Basic hypotheses}

This study is performed using the specialised finite element code SAFIR [6], which is a finite element code for geometrical and material non-linear analysis, specially developed at the University of Liege for studying structures subjected to fire.

A three-dimensional (3D) beam element has been used, based on the following formulations and hypotheses: 

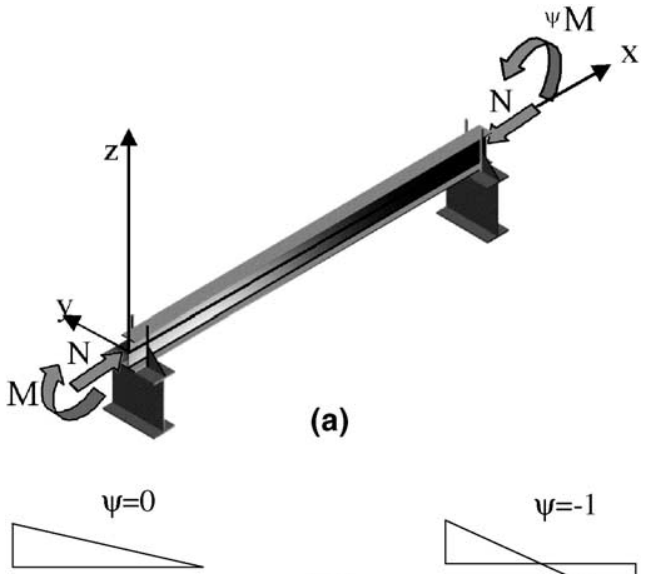

(b)

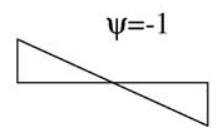

Fig. 1. (a) Simply supported beam-column with non-uniform bending; (b) studied bending diagrams.

- Displacement type element in a total co-rotational description.

- Prismatic element.

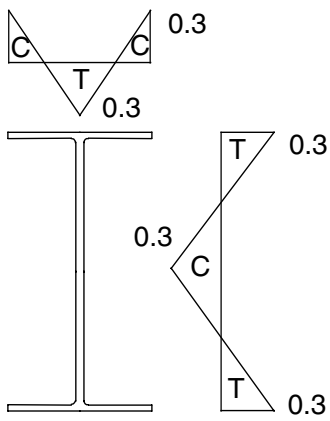

Fig. 2. Residual stresses: $\mathrm{C}$-compression; $\mathrm{T}$ - tension.

- The displacement of the node line is described by the displacements of the three nodes of the element, two nodes at each end supporting seven degrees of freedom, three translations, three rotations and the warping amplitude, plus one node at the mid-length supporting one degree of freedom, namely the non-linear part of the longitudinal displacement.
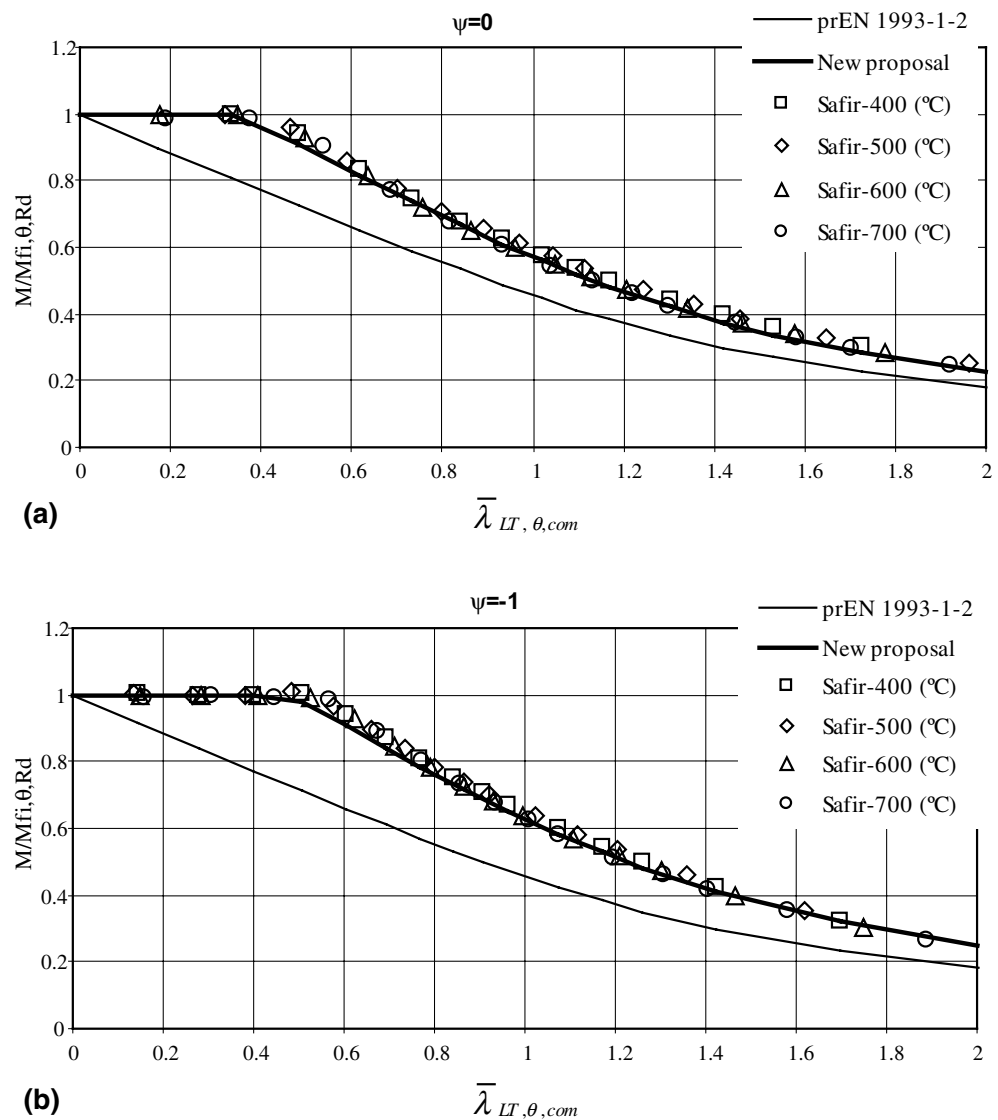

Fig. 3. Beam design curve from the prEN 1993-1-2, and the new proposal: (a) $\psi=0$; (b) $\psi=-1$. 
- The Bernoulli hypothesis is considered, i.e., in bending, plane sections remain plane and perpendicular to the longitudinal axis and no shear deformation is considered.

- No local buckling is taken into account, which is the reason why only Class 1 and Class 2 sections can be used [1].

- The strains are small (von Kármán hypothesis), i.e.,

$\frac{1}{2} \frac{\partial u}{\partial x} \ll 1$

where $u$ is the longitudinal displacement and $x$ is the longitudinal co-ordinate.

- The angles between the deformed longitudinal axis and the undeformed but translated longitudinal axis are small, i.e.,

$\sin \varphi \cong \varphi$ and $\cos \varphi \cong 1$ where $\varphi$ is the angle between the arc and the chord of the translated beam finite element.

- The longitudinal integrations are numerically calculated using Gauss' method.

- The cross-section is discretised by means of triangular or quadrilateral fibres. At every longitudinal point of integration, all variables, such as temperature, strain, stress, etc., are uniform in each fibre.

- The tangent stiffness matrix is evaluated at each iteration during the convergence process (pure NewtonRaphson method).

- Residual stresses are considered by means of initial and constant strains [7].

- The material behaviour in case of strain unloading is elastic, with the elastic modulus equal to the Young modulus at the origin of the stress-strain curve. In

Table 1

Correction factors $k_{\mathrm{c}}$ for the new proposal

\begin{tabular}{ll}
\hline Moment distribution & $\frac{\text { Class } 1,2,3 \text { sections }}{k_{\mathrm{c}}}$ \\
\hline$M_{\square} \psi M-1 \leqslant \psi \leqslant 1$ & $0.6+0.3 \psi+0.15 \psi^{2}$ but $k_{\mathrm{c}} \leqslant 1$ \\
\hline
\end{tabular}
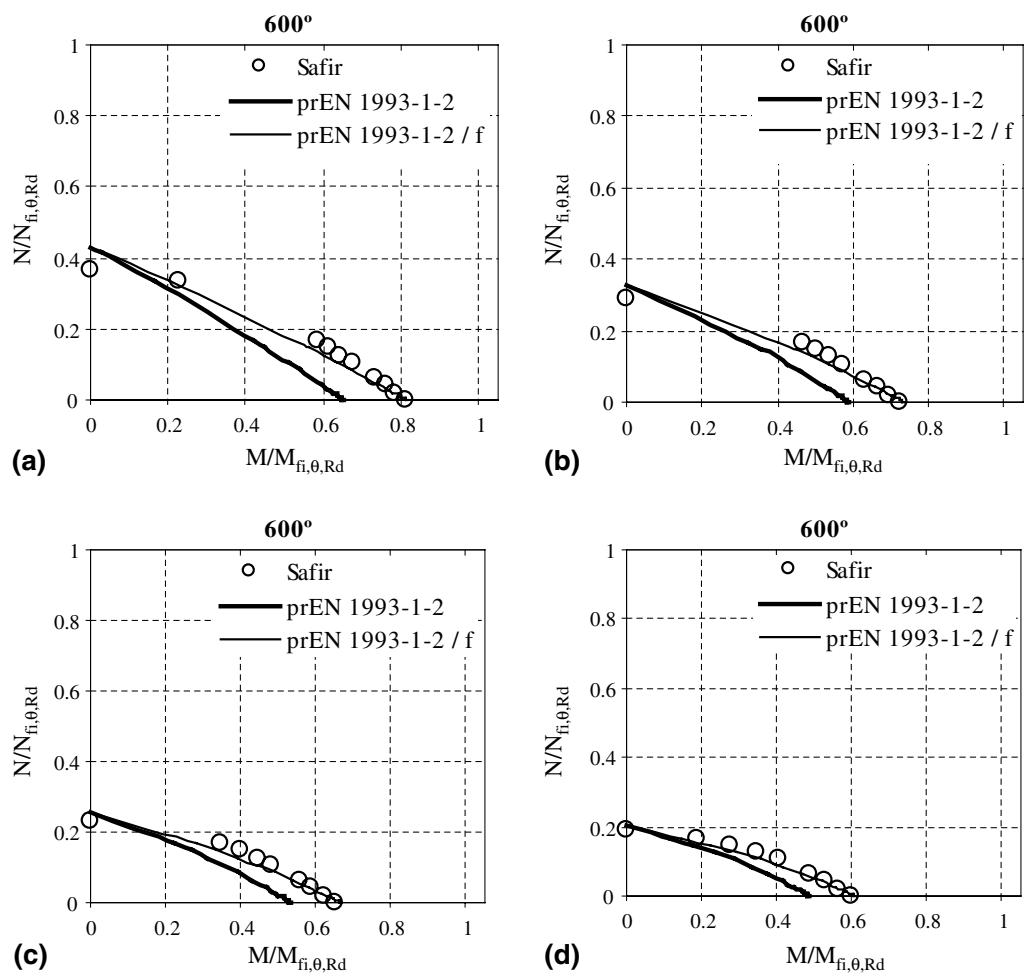

Fig. 4. Interaction diagrams of prEN 1993-1-2, for $\psi=0$ : (a) $L=2000 \mathrm{~mm}, \bar{\lambda}_{\mathrm{LT}, \mathrm{fi}}=0.62, \bar{\lambda}_{y, \mathrm{fi}}=0.29$, $\bar{\lambda}_{z, \mathrm{fi}}=1.06$; (b) $L=2500 \mathrm{~mm}$, $\bar{\lambda}_{\mathrm{LT}, \mathrm{fi}}=0.73, \bar{\lambda}_{y, \mathrm{fi}}=0.36, \bar{\lambda}_{z, \mathrm{fi}}=1.32$; (c) $L=3000 \mathrm{~mm}, \bar{\lambda}_{\mathrm{LT}, \mathrm{fi}}=0.84, \bar{\lambda}_{y, \mathrm{fi}}=0.43, \bar{\lambda}_{z, \mathrm{fi}}=1.59$; (d) $L=3500 \mathrm{~mm}, \bar{\lambda}_{\mathrm{LT}, \mathrm{fi}}=0.93, \bar{\lambda}_{y, \mathrm{fi}}=0.50$, $\bar{\lambda}_{z, \mathrm{fi}}=1.85$. 
the same cross-section, some fibres that have yielded may therefore exhibit a decreased tangent modulus because they are still on the loading branch, whereas, at the same time, some other fibres behave elastically. The plastic strain is presumed not to be affected by a change in temperature [8].

- The elastic torsional stiffness at $20^{\circ} \mathrm{C}$, which is calculated by the code, has been adapted in an iterative process in order to reflect the decrease of material stiffness at the critical temperature [9].

\subsection{Case study}

A simply supported beam-column with fork supports has been chosen to explore the validity of the beam safety conditions, as shown in Fig. 1a. With respect to the bending moment variation along the member length, two values, $(-1,0)$, of the $\psi$ ratio (see Fig. 1) have been investigated.

The case $\psi=1$ was not studied here because this case is not affected by the new procedure for lateral-torsional buckling [5], that is, when the $\psi$ ratio equals 1 , the proposed formulae for the evaluation of the lateraltorsional buckling resistance of steel beams remains the same as those proposed in the prEN 1993-1-2. The parametric study of beam-columns for $\psi=1$ has already been made by Vila Real et al. [4].

An IPE 220 _eel section of grade S 235 has been used. Uniform temperature in the cross-section has been also used so that comparison between the numerical results and the eurocode could be made. In this paper the temperature used was $600{ }^{\circ} \mathrm{C}$, deemed to adequately represent the majority of practical situations.

A lateral geometric imperfection given by the following expression was considered:

$y(x)=\frac{l}{1000} \sin \left(\frac{\pi x}{l}\right)$

where $l$ is the beam length. An initial rotation with a maximum value of $l / 1000 \mathrm{rad}$ at mid span was also introduced.

The residual stresses adopted are constant across the thickness of the web and flanges. A triangular distribution as shown in Fig. 2, with a maximum value of $0.3 \times 235 \mathrm{MPa}$, for the $\mathrm{S} 235$ steel has been used [10].

The lengths of the studied elements, were chosen so that the adimensional slenderness were smaller than 2 .
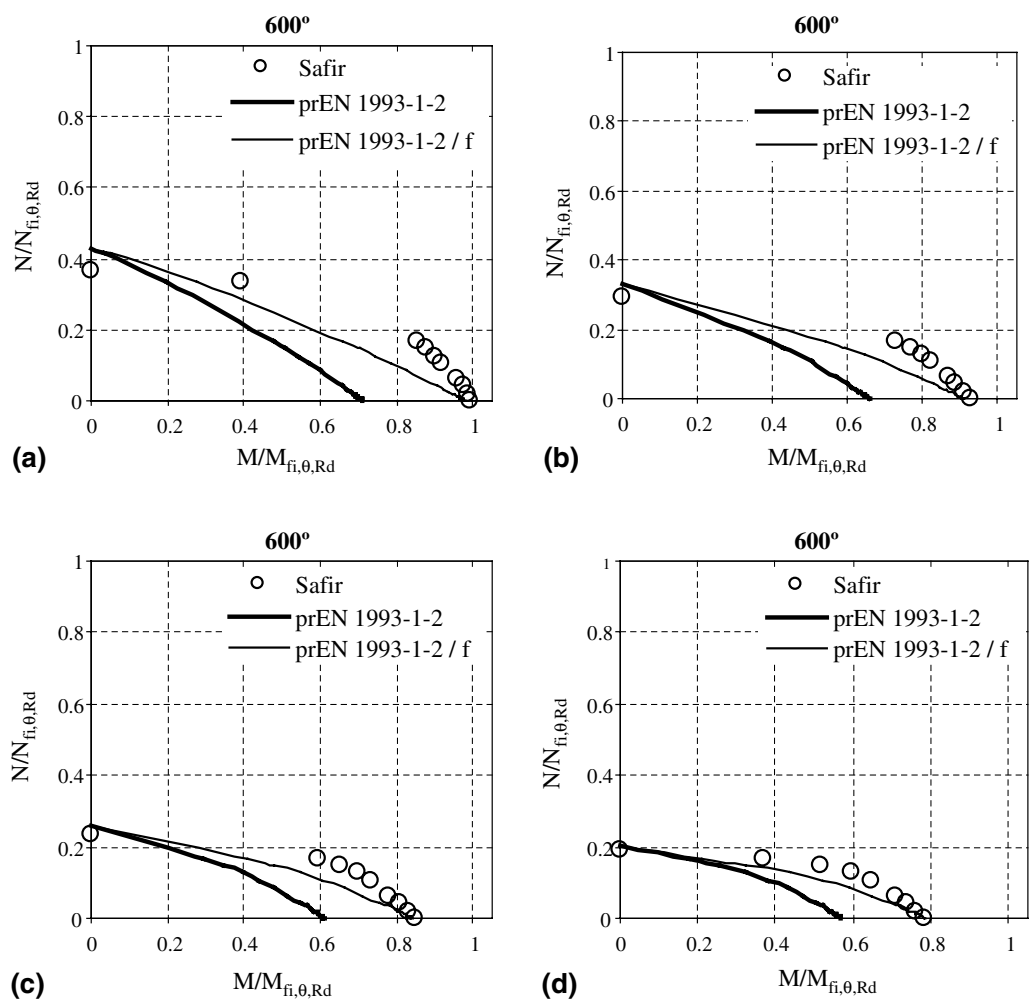

Fig. 5. Interaction diagrams of prEN 1993-1-2, for $\psi=-1$ : (a) $L=2000 \mathrm{~mm}, \bar{\lambda}_{\mathrm{LT}, \mathrm{fi}}=0.51, \bar{\lambda}_{y, \mathrm{fi}}=0.29, \bar{\lambda}_{z, \mathrm{fi}}=1.06$; (b) $L=2500 \mathrm{~mm}$, $\bar{\lambda}_{\mathrm{LT}, \mathrm{fi}}=0.61, \bar{\lambda}_{y, \mathrm{fi}}=0.36, \bar{\lambda}_{z, \mathrm{fi}}=1.32$; (c) $L=3000 \mathrm{~mm}, \bar{\lambda}_{\mathrm{LT}, \mathrm{fi}}=0.69, \bar{\lambda}_{y, \mathrm{fi}}=0.43, \bar{\lambda}_{z, \mathrm{fi}}=1.59$; (d) $L=3500 \mathrm{~mm}, \bar{\lambda}_{\mathrm{LT}, \mathrm{fi}}=0.77, \bar{\lambda}_{y, \mathrm{fi}}=0.50$, $\bar{\lambda}_{z, \mathrm{fi}}=1.85$. 


\section{Improvement of the prEN 1993-1-2 proposal for lateral-torsional buckling}

According to the proposal of prEN 1993-1-2 [2], the design lateral-torsional buckling resistance of a laterally unrestrained beam with Class 1 or 2 cross-section, is obtained as follows:

$M_{\mathrm{b}, \mathrm{fi}, \mathrm{t}, \mathrm{Rd}}=\chi_{\mathrm{LT}, \mathrm{fi}} W_{\mathrm{pl}, y} k_{y, \theta, \mathrm{com}} f_{y} \frac{1}{\gamma_{\mathrm{M}, \mathrm{fi}}}$

where $\chi_{\mathrm{LT}, \mathrm{fi}}$ is given by

$\chi_{\mathrm{LT}, \mathrm{fi}}=\frac{1}{\phi_{\mathrm{LT}, \theta, \mathrm{com}}+\sqrt{\left[\phi_{\mathrm{LT}, \theta, \mathrm{com}}\right]^{2}-\left[\bar{\lambda}_{\mathrm{LT}, \theta, \mathrm{com}}\right]^{2}}}$

with

$\phi_{\mathrm{LT}, \theta, \mathrm{com}}=\frac{1}{2}\left[1+\alpha \bar{\lambda}_{\mathrm{LT}, \theta, \mathrm{com}}+\left(\bar{\lambda}_{\mathrm{LT}, \theta, \mathrm{com}}\right)^{2}\right]$

where $k_{y, \theta, \text { com }}$ is the reduction factor for the yield strength at the maximum temperature in the compression flange $\theta_{a, \text { com }}$ reached at time $t ; \gamma_{\mathrm{M} \text {.fi }}$ is the partial safety factor for the fire situation (usually $\gamma_{\mathrm{M}, \mathrm{fi}}=1$ ).
The non-dimensional slenderness $\bar{\lambda}_{\mathrm{LT}, \theta, \text { com }}$ (or $\bar{\lambda}_{\mathrm{LT}, \mathrm{fi}}$, if the temperature field in the cross-section is uniform) is given by

$\bar{\lambda}_{\mathrm{LT}, \theta, \mathrm{com}}=\bar{\lambda}_{\mathrm{LT}, \mathrm{fi}}=\bar{\lambda}_{\mathrm{LT}} \sqrt{\frac{k_{y, \theta, \mathrm{com}}}{k_{\mathrm{E}, \theta, \mathrm{com}}}}$

where $k_{\mathrm{E}, \theta, \text { com }}$ is the reduction factor for the slope of the linear elastic range at the maximum steel temperature reached at time $t$.

In this proposal, the imperfection factor $\alpha$ is a function of the steel grade and is given by:

$\alpha=0.65 \sqrt{235 / f_{y}}$

As shown in Fig. 3, for the two values of the $\psi$ ratio, -1 and 0, these formulae (from prEN 1993-1-2) lead to over-conservative results when compared to numerical results for the case of non-uniform bending. To avoid these over-conservative results, Vila Real et al. [5] have made a new proposal that adopts a modified reduction factor for lateral-torsional buckling, $\chi_{\mathrm{LT}, \mathrm{fi}, \mathrm{mod}}$, given by
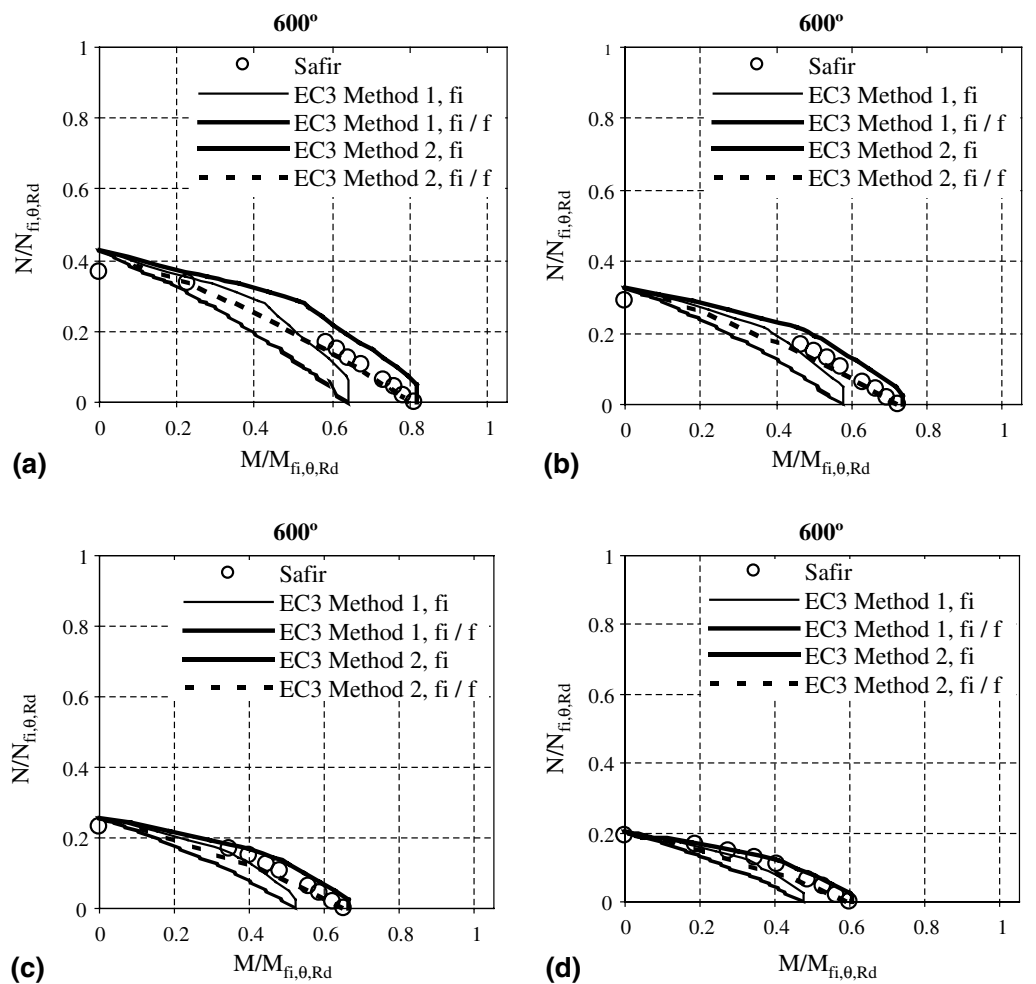

Fig. 6. Interaction diagrams of prEN 1993-1-1 at $600{ }^{\circ} \mathrm{C}$ for $\psi=0$ : (a) $L=2000 \mathrm{~mm}, \bar{\lambda}_{\mathrm{LT}, \mathrm{fi}}=0.62, \bar{\lambda}_{y, \mathrm{fi}}=0.29, \bar{\lambda}_{z, \mathrm{fi}}=1.06$; (b) $L=2500 \mathrm{~mm}, \bar{\lambda}_{\mathrm{LT}, \mathrm{fi}}=0.73, \bar{\lambda}_{y, \mathrm{fi}}=0.36, \bar{\lambda}_{z, \mathrm{fi}}=1.32$; (c) $L=3000 \mathrm{~mm}, \bar{\lambda}_{\mathrm{LT}, \mathrm{fi}}=0.84, \bar{\lambda}_{y, \mathrm{fi}}=0.43, \bar{\lambda}_{z, \mathrm{fi}}=1.59$; (d) $L=3500 \mathrm{~mm}$, $\bar{\lambda}_{\mathrm{LT}, \mathrm{fi}}=0.93, \bar{\lambda}_{y, \mathrm{fi}}=0.50, \bar{\lambda}_{z, \mathrm{fi}}=1.85$. 
$\chi_{\mathrm{LT}, \mathrm{fi}, \text { mod }}=\frac{\chi_{\mathrm{LT}, \mathrm{fi}}}{f}$ but $\chi_{\mathrm{LT}, \mathrm{fi}, \text { mod }} \leqslant 1$

where $f$ depends on the loading type and is given by the following equation

$f=1-0.5\left(1-k_{\mathrm{c}}\right)$

where $k_{\mathrm{c}}$ is a correction factor according to Table 1 .

As it can be seen in Fig. 3, this new proposal shows a very good agreement with the numerical results.

\section{Interaction formulae for beam-columns at high tem- peratures}

\subsection{Interaction formulae proposed by prEN 1993-1-2}

For fire loading, according to the new version of part 1-2 of Eurocode 3 [2], the interaction equations for beam-columns are:

$\frac{N_{\mathrm{fi}, \mathrm{Ed}}}{\chi_{z, \mathrm{fi}} A k_{y, \theta} \frac{f_{y}}{\gamma_{\mathrm{M}, \mathrm{i}}}}+\frac{K_{\mathrm{LT}} M_{y, \mathrm{fi}, \mathrm{Ed}}}{\chi_{\mathrm{LT}, \mathrm{fi}} W_{\mathrm{pl}, y} k_{y, \theta} \frac{f_{y}}{\gamma_{\mathrm{M}, \mathrm{fi}}}} \leqslant 1$

where
$K_{\mathrm{LT}}=1-\frac{\mu_{\mathrm{LT}} N_{\mathrm{fi}, \mathrm{Ed}}}{\chi_{z, \mathrm{fi}} A k_{y, \theta} \frac{f_{y}}{\gamma_{\mathrm{M} . \mathrm{ii}}}} \quad$ but $K_{\mathrm{LT}} \leqslant 1.0$

and

$\mu_{\mathrm{LT}}=0.15 \bar{\lambda}_{z, \theta} \beta_{\mathrm{M}, \mathrm{LT}}-0.15$ but $\mu \leqslant 0.9$

Here $\chi_{\mathrm{fi}}$ are the reduction factors for flexural buckling around the $y y$ and $z z$ axis, and $\chi_{\mathrm{LT}, \mathrm{fi}}$ is the reduction factor for lateral-torsional buckling, given by (4).

These formulae for the design of beam-columns are based on the ENV 1993-1-1 (1992) [3].

To study the described methods, for each selected beam-column length and bending moment ratio $\psi(0,-1)$, illustrated in Fig. 3, the interaction equation (10) was plotted for increasing ratios of $N / N_{\mathrm{fi}, \theta, \mathrm{Rd}}$, together with the results of the numerical simulations for a uniform temperature of $600{ }^{\circ} \mathrm{C}$, as shown in Figs. 4 and 5. In these figures, the results from equation (10) are denoted by "prEN 1993-1-2" whenever the new proposal for LTB is not considered and "prEN 1993-1-2/f" otherwise.

From Figs. 4 and 5 it is concluded that the new proposal for LTB introduces a significant improvement
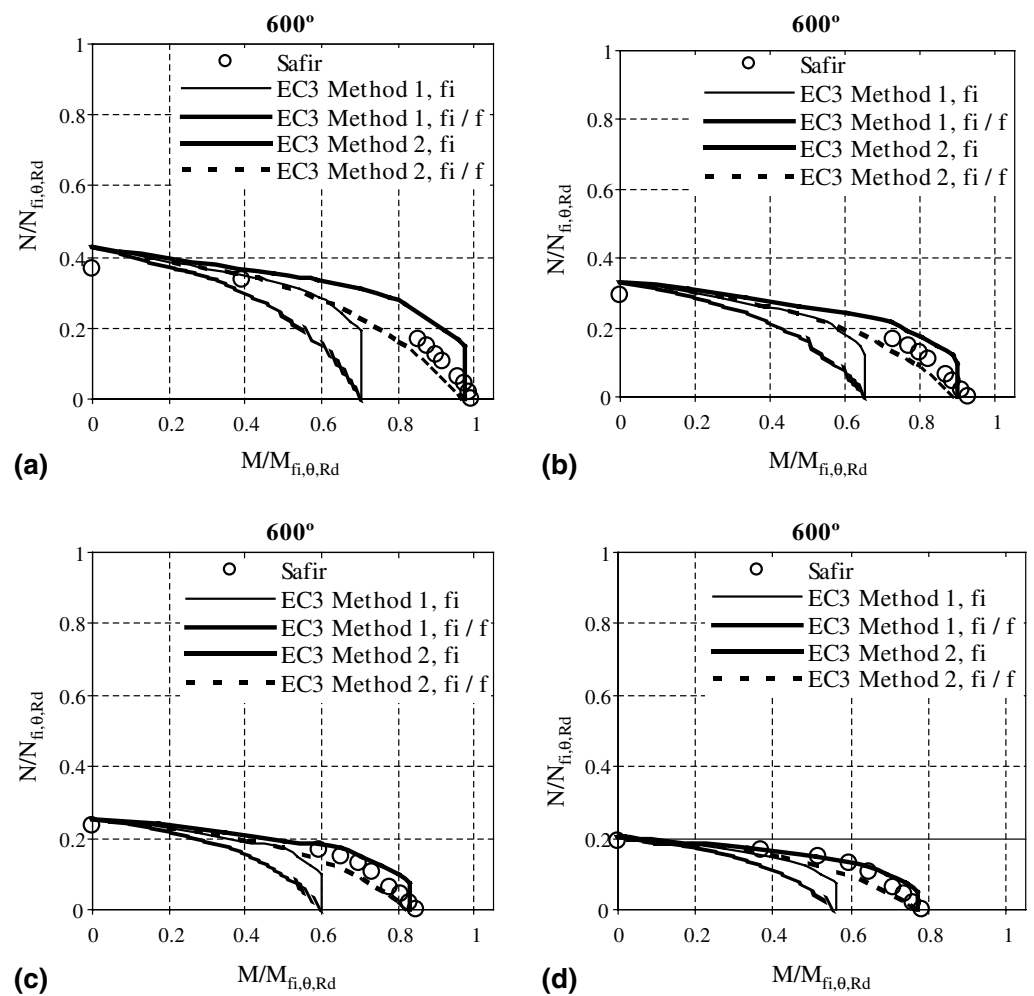

Fig. 7. Interaction diagrams of prEN $1993-1-1$ at $600{ }^{\circ} \mathrm{C}$ for $\psi=-1$ : (a) $L=2000 \mathrm{~mm}, \bar{\lambda}_{\mathrm{LT} . \mathrm{fi}}=0.51, \bar{\lambda}_{y . f \mathrm{i}}=0.29, \bar{\lambda}_{z, \mathrm{fi}}=1.06$; (b) $L=2500 \mathrm{~mm}, \bar{\lambda}_{\mathrm{LT}, \mathrm{fi}}=0.61, \bar{\lambda}_{y, \mathrm{fi}}=0.36, \bar{\lambda}_{z, \mathrm{fi}}=1.32$; (c) $L=3000 \mathrm{~mm}, \bar{\lambda}_{\mathrm{LT}, \mathrm{fi}}=0.69, \bar{\lambda}_{y, \mathrm{fi}}=0.43, \bar{\lambda}_{z, \mathrm{fi}}=1.59$; (d) $L=3500 \mathrm{~mm}$, $\bar{\lambda}_{\mathrm{LT}, \mathrm{fi}}=0.77, \bar{\lambda}_{y, \mathrm{fi}}=0.50, \bar{\lambda}_{z, \mathrm{fi}}=1.85$. 
in the interaction diagrams, for beam-columns with lateral-torsional buckling.

\subsection{Proposed interaction formulae based on prEN 1993- 1-1 proposal}

Vila Real et al. [4] have proposed the following interaction formulae for beam-columns in case of fire:

$\frac{N_{\mathrm{fi}, \mathrm{Ed}}}{\chi_{y, \mathrm{fi}} \frac{N_{\mathrm{fi}, \mathrm{Rk}}}{\gamma_{\mathrm{M}, \mathrm{fi}}}}+k_{y y, \mathrm{fi}} \frac{M_{y, \mathrm{fi}, \mathrm{Ed}}+\Delta M_{y, \mathrm{fi}, \mathrm{Ed}}}{\chi_{\mathrm{LT}, \mathrm{fi}} \frac{M_{y, \mathrm{fi}, \mathrm{Rk}}}{\gamma_{\mathrm{M}, \mathrm{fi}}}} \leqslant 1$

$\frac{N_{\mathrm{fi}, \mathrm{Ed}}}{\chi_{z, \mathrm{fi}} \frac{N_{\mathrm{fi}, \mathrm{Rk}}}{\gamma_{\mathrm{M}, \mathrm{fi}}}}+k_{z y, \mathrm{fi}} \frac{M_{y, \mathrm{fi}, \mathrm{Ed}}+\Delta M_{y, \mathrm{fi}, \mathrm{Ed}}}{\chi_{\mathrm{LT}, \mathrm{fi}} \frac{M_{y, \mathrm{fi} \mathrm{Rk}}}{\gamma_{\mathrm{M}, \mathrm{fi}}}} \leqslant 1$

where $\chi_{\mathrm{fi}}$ are the reduction factors for flexural buckling around the $y y$ and $z z$ axes, and $\chi_{\mathrm{LT}, \mathrm{fi}}$ is the reduction factor for lateral-torsional buckling, calculated according to (4).

These interaction formulae are based on the prEN 1993-1-1 provided that some factors are changed to take into consideration high temperatures. The factors changed were the yield stress, the Young modulus, and the reduction factors $\chi_{\mathrm{fi}}$ for flexural buckling around the $y y$ and $z z$ axes, and $\chi_{\mathrm{LT}, \mathrm{fi}}$ for lateral-torsional buckling according to the proposals of prEN 1993-1-2.

The factors $k_{y y \text {,fi }}$ and $k_{z y \text {,fi }}$ are the interaction factors in case of fire that can be determined by two alternative methods ("EC3 Method 1, fi" and "EC3 Method 2, fi") described in Vila Real et al. [4]. Also, if the new proposal of Vila Real et al. [5] for lateral-torsional buckling is used, two additional methods are obtained ("EC3 Method 1, fi/f”' and 'EC3 Method 2, fi/f') all illustrated in Figs. 6-9.

The procedure for the evaluation of the interaction factors for "EC3 Method 1, fi" is based on method 1 at room temperature, that is reported in Annex A of part 1.1 of EC3 [1] and was developed by a French-Belgian team [11] combining theoretical rules and numerical calibration to account for all the differences between the real model and the theoretical one. The specific formulae for the calculation of the interaction factors according to method 1 in case of fire are:

$k_{y y, \mathrm{fi}}=c_{m y, \mathrm{fi}} c_{m \mathrm{LT}, \mathrm{fi}} \frac{\mu_{y, \theta}}{1-\frac{N_{\mathrm{fi}, \mathrm{Ed}}}{N_{\mathrm{cr}, y \mathrm{fi}}}} \cdot \frac{1}{c_{y y, \mathrm{fi}}}$
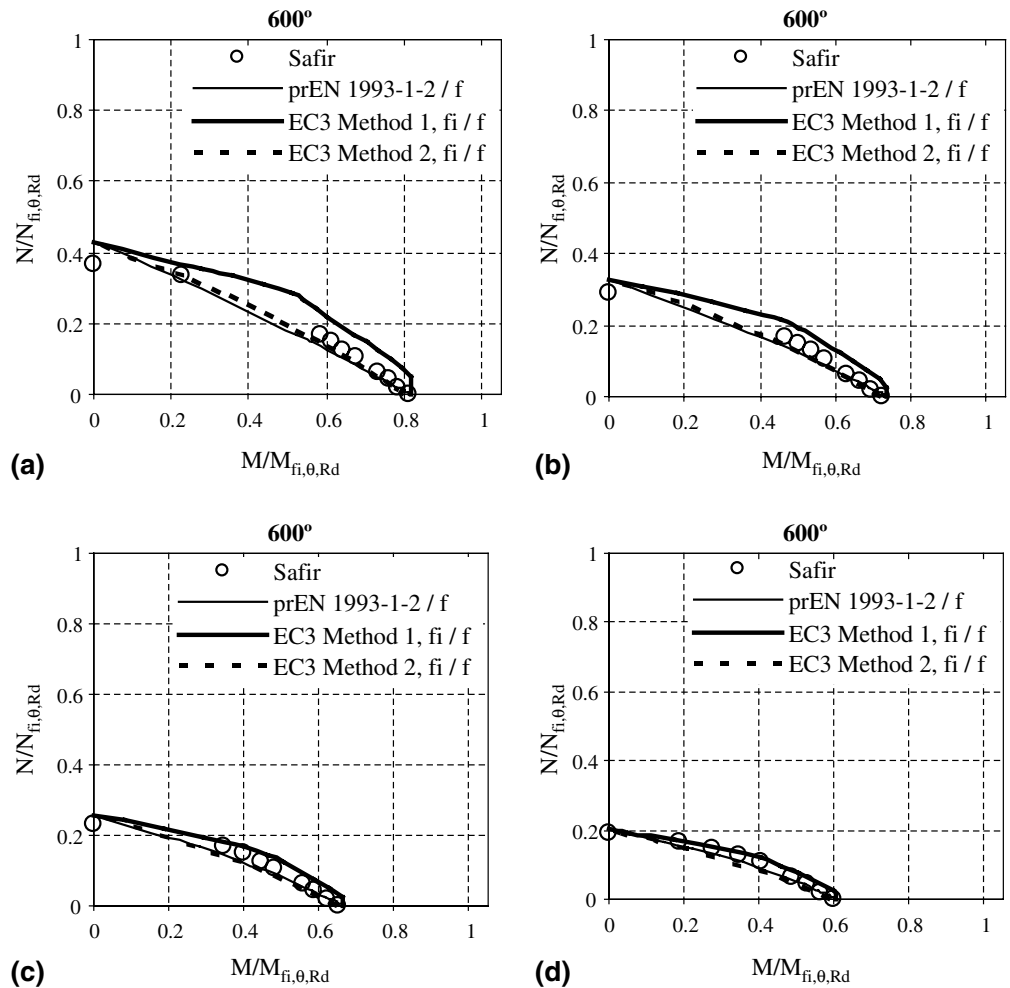

Fig. 8. Interaction diagrams considering the new proposal for lateral-torsional buckling, for $\psi=0$ : (a) $-L=2000 \mathrm{~mm}, \bar{\lambda}_{\mathrm{LT}, \mathrm{fi}}=0.62$, $\bar{\lambda}_{y, \mathrm{fi}}=0.29, \bar{\lambda}_{z, \mathrm{fi}}=1.06$; (b) $-L=2500 \mathrm{~mm}, \bar{\lambda}_{\mathrm{LT}, \mathrm{fi}}=0.73, \bar{\lambda}_{y, \mathrm{fi}}=0.36, \bar{\lambda}_{z, \mathrm{fi}}=1.32$; (c) $-L=3000 \mathrm{~mm}, \bar{\lambda}_{\mathrm{LT}, \mathrm{fi}}=0.84, \bar{\lambda}_{y, \mathrm{fi}}=0.43$, $\bar{\lambda}_{z, \mathrm{fi}}=1.59 ;(\mathrm{d})-L=3500 \mathrm{~mm}, \bar{\lambda}_{\mathrm{LT}, \mathrm{fi}}=0.93, \bar{\lambda}_{y, \mathrm{fi}}=0.50, \bar{\lambda}_{z, \mathrm{fi}}=1.85$. 

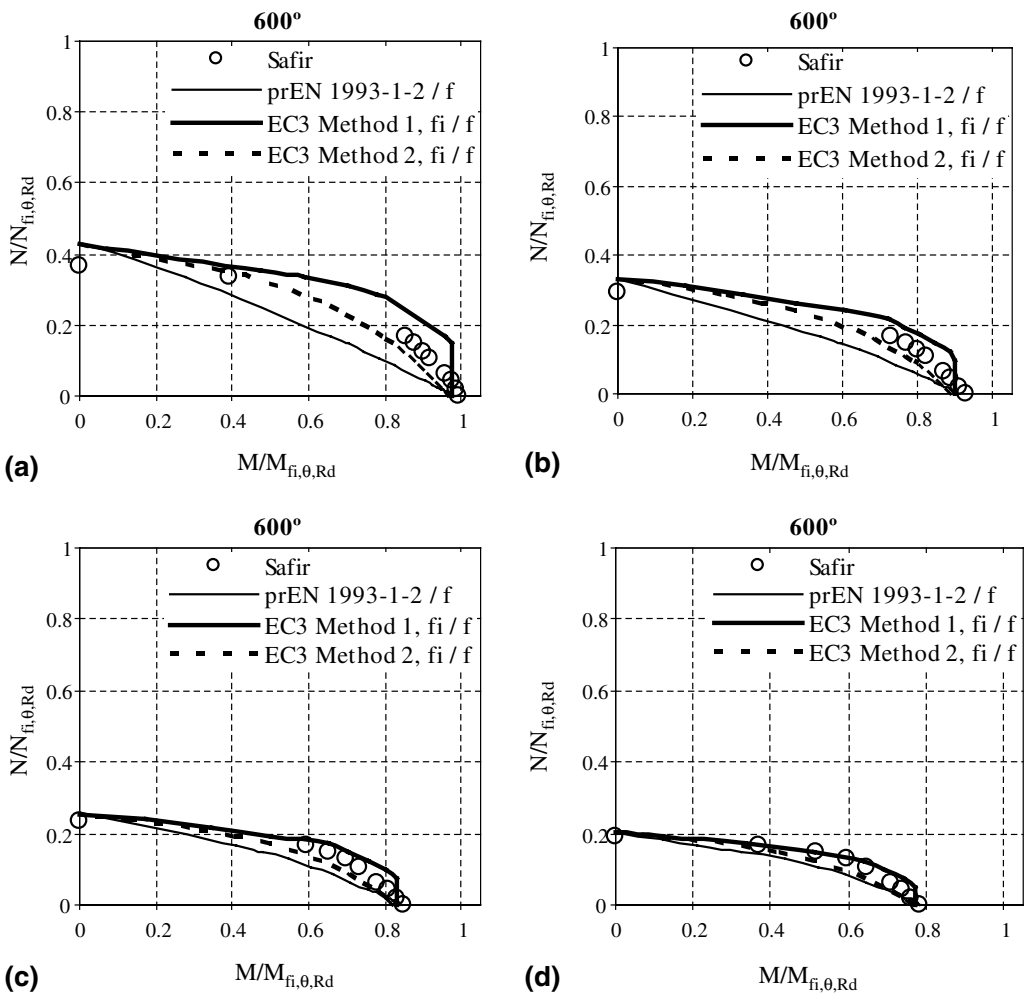

Fig. 9. Interaction diagrams considering the new proposal for lateral-torsional buckling, for $\psi=-1:$ (a) $-L=2000 \mathrm{~mm}, \bar{\lambda}_{\mathrm{LT}, \mathrm{fi}}=0.51$, $\bar{\lambda}_{y, \mathrm{fi}}=0.29, \bar{\lambda}_{z, \mathrm{fi}}=1.06$; (b) $-L=2500 \mathrm{~mm}, \bar{\lambda}_{\mathrm{LT}, \mathrm{fi}}=0.61, \bar{\lambda}_{y, \mathrm{fi}}=0.36, \bar{\lambda}_{z, \mathrm{fi}}=1.32$; (c) $-L=3000 \mathrm{~mm}, \bar{\lambda}_{\mathrm{LT}, \mathrm{fi}}=0.69, \bar{\lambda}_{y, \mathrm{fi}}=0.43$, $\bar{\lambda}_{z, \mathrm{fi}}=1.59 ;(\mathrm{d})-L=3500 \mathrm{~mm}, \bar{\lambda}_{\mathrm{LT}, \mathrm{fi}}=0.77, \bar{\lambda}_{y, \mathrm{fi}}=0.50, \bar{\lambda}_{z, \mathrm{fi}}=1.85$.

$k_{z y, \mathrm{fi}}=c_{m y, \mathrm{fi}} c_{m \mathrm{LT}, \mathrm{fi}} \frac{\mu_{z, \theta}}{1-\frac{N_{\mathrm{fi}, \mathrm{Ed}}}{N_{\mathrm{cr}, y, \mathrm{fi}}}} \cdot \frac{1}{c_{z y, \mathrm{fi}}} 0.6 \sqrt{\frac{w_{y}}{w_{z}}}$

$c_{m y, \mathrm{fi}}=c_{m y, \mathrm{fi}, 0}+\left(1-c_{m y, \mathrm{fi}, 0}\right) \frac{\sqrt{\varepsilon_{y, \mathrm{fi}}} a_{\mathrm{LT}}}{1+\sqrt{\varepsilon_{y, \mathrm{fi}}} a_{\mathrm{LT}}}$

$c_{m \mathrm{LT}, \mathrm{fi}}=c_{m y, \mathrm{fi}}^{2} \frac{a_{\mathrm{LT}}}{\sqrt{\left(1-\frac{N_{\mathrm{fi}, \mathrm{Ed}}}{N_{\mathrm{cr}, z \mathrm{fi}}}\right)\left(1-\frac{N_{\mathrm{fi}, \mathrm{Ed}}}{N_{\mathrm{cr}, \mathrm{T}, \mathrm{fi}}}\right)}}$

$\varepsilon_{y, \mathrm{fi}}=\frac{M_{y, \mathrm{fi}, \mathrm{Ed}}}{N_{\mathrm{fi}, \mathrm{Ed}}} \cdot \frac{A}{W_{\mathrm{el}, y}}$

Due to the non-linearity introduced by the factor $\varepsilon_{y}$ the interaction curves were obtained using an iterative procedure. It was assumed that the moment of each studied beam-column could not exceed its design buckling resistance moment, $M_{\mathrm{b}, \mathrm{Rd}, \mathrm{fi}}$. This justifies the vertical branch of some interaction curves of method 1 .

"EC3 Method 2, fi" is related to method 2 at room temperature, which is described in Annex B of part 1.1 of EC3 [1] and results from an Austrian-German proposal [12] that attempted to simplify the verification of the stability of beam-columns, all interaction factors being obtained by means of numerical calibration. These factors are not clearly understandable from a physical point of view, but this simple formulation simplifies the verification procedure and reduces the possibility of mistakes.

The interaction factors according to method 2 in case of fire should be calculated from:

$$
\begin{aligned}
k_{y y, \mathrm{fi}}= & c_{m y, \mathrm{fi}}\left(1+\left(\bar{\lambda}_{y, \theta}-0.2\right) \frac{N_{\mathrm{fi}, \mathrm{Ed}}}{\chi_{y, \mathrm{fi}} \frac{N_{\mathrm{fi}, \mathrm{Rk}}}{\gamma_{\mathrm{M}, \mathrm{fi}}}}\right) \\
& \leqslant c_{m y, \mathrm{fi}}\left(1+0.8 \frac{N_{\mathrm{fi}, \mathrm{Ed}}}{\chi_{y, \mathrm{fi}}}\right) \\
k_{\mathrm{fi}, \mathrm{Rk}} & \left.1-\frac{0.1 \bar{\lambda}_{z, \theta}}{c_{m, \mathrm{fi}}}\right) \\
\geqslant & 1-\frac{N_{\mathrm{fi}, \mathrm{Ed}}-0.25}{\chi_{z, \mathrm{fi}} \frac{N_{\mathrm{fi}, \mathrm{Rk}}}{\gamma_{\mathrm{M}, \mathrm{fi}}}} \\
c_{m \mathrm{LT}}-0.25 & \frac{N_{\mathrm{fi}, \mathrm{Ed}}}{\chi_{z, \mathrm{fi}} \frac{N_{\mathrm{fi}, \mathrm{Rk}}}{\gamma_{\mathrm{M}, \mathrm{fi}}}} \quad \text { for } \bar{\lambda}_{z, \theta}<0.4 \\
k_{z y}= & 0.6+\bar{\lambda}_{z, \theta} \leqslant 1-\frac{0.1 \bar{\lambda}_{z, \theta}}{c_{m \mathrm{LT}}-0.25} \cdot \frac{N_{\mathrm{fi}, \mathrm{Ed}}}{\chi_{z, \mathrm{fi}} \frac{N_{\mathrm{fi}, \mathrm{Rk}}}{\gamma_{\mathrm{M}, \mathrm{fi}}}}
\end{aligned}
$$


where

$c_{m i, \mathrm{fi}}=0.6+0.4 \psi_{i} \geqslant 0.4$

Figs. 6 and 7 show the influence of considering or not the new proposal for LTB [5] with method 1 and method 2 adapted to elevated temperatures, for $\psi=0$ and $\psi=-1$ respectively. It can be observed in those figures that the new proposal for LTB introduces a great improvement in the interaction diagrams for both methods.

Finally in Figs. 8 and 9, all the three methods studied here, considering the new proposal for the lateral-torsional buckling of beams [5] are plotted together, showing a very good agreement with the numerical results.

\section{Conclusions}

It has been shown that the proposed methods for the lateral-torsional buckling of unrestrained steel beams at high temperatures, introduce significant improvements in the design curves of beam-columns under fire conditions.

If method 1 and method 2 are adopted, there is the advantage of using the same formulae at room temperature and at elevated temperature, being in line with the procedure always adopted in the Eurocodes. The results have shown that the method 1 sometimes is not in the safe side. These aspects should be considered when the new proposal for the resistance of beam-columns has to be chosen in the next revision of the Eurocode 3 .

Although the study presented in this paper recommends the use of one of these proposals in future versions of part 1-2 of the Eurocode 3, more numerical and experimental tests are needed, so that the validity of these proposals can be thoroughly assessed, namely the use of different steel grades and cross-sectional shapes.

\section{References}

[1] Eurocode 3, Design of Steel Structures-part 1-1. General rules and rules for buildings. prEN 1993-1-1:2003, Stage 49
Draft, European Committee for Standardisation, Brussels, Belgium, May 2003.

[2] Eurocode 3, Design of Steel Structures-part 1-2. General rules-Structural fire design. Draft prEN 1993-1-2:2003, Stage 49 Draft, European Committee for Standardisation, Brussels, Belgium, April 2003.

[3] Eurocode 3, Design of Steel Structures-part 1-1. General rules and rules for buildings. ENV 1993-1-1, Commission of the European Communities, Brussels, Belgium, 1992.

[4] Vila Real PMM, Lopes N, Simões da Silva L, Piloto P, Franssen J-M. Towards a consistent safety format of steel beam-columns: application of the new interaction formulae for ambient temperature to elevated temperatures. Steel Compos Struct 2003;3(6):383-401.

[5] Vila Real PMM, Lopes N, Simões da Silva L, Franssen J-M. Lateral-torsional buckling of unrestrained steel beams under fire conditions: improvement of EC3 proposal. Comput Struct, in press.

[6] Franssen J-M. SAFIR. A thermal/structural program modeling structures under fire. In: Proc NASCC Conference, American Inst for Steel Constr, Baltimore, April 2003.

[7] Franssen J-M. Modelling of the residual stresses influence in the behaviour of hot-rolled profiles under fire conditions in French Construct Métall 1989;3:35-42.

[8] Franssen JM. The unloading of building materials submitted to fire. Fire Safety J 1990;16:213-27.

[9] Souza V, Franssen J-M. Lateral buckling of steel I beams at elevated temperature - comparison between the modelling with beam and shell elements. In: Lamas A, Simões da Silva L, editors. Proc 3rd European Conf on Steel Structures, Coimbra: Univ. de Coimbra; 2002. p. 147988. ISBN: 972-98376-3-5.

[10] ECCS-European Convention for Constructional Steelwork, Technical Committee 8-Structural Stability, Technical Working Group 8.2-System, "Ultimate Limit State Calculation of Sway Frames With Rigid Joints", 1st ed., 1984.

[11] Boissonnade N, Jaspart J-P, Muzeau J-P, Villette M. New interaction formulae for beam-columns in Eurocode 3: the French-Belgian approach. J Construct Steel Res 2004;60(3-5):421-31.

[12] Greiner R. Background information on the beam-column interaction formulae at level 1, ECCS TC 8. Ad-hoc working group on beam-columns paper No. TC8-2001, Technical University Graz, 19 September 2001. 